\title{
EFFECTIVITY OF NINTENDO WII AS REHABILITATION THERAPY IN POST STROKE PATIENTS: A SYSTEMATIC REVIEW
}

\author{
Rachmawati Wardani ${ }^{1}$, Sirin Salsabila ${ }^{2}$, Arizal Novrianto ${ }^{3}$, Rodhiyan Rakhmatiar ${ }^{4}$ \\ Correspondence: rahmaawardani@gmail.com \\ ${ }^{I}$ Medical Intern Hasta Brata Hospital, Batu, Indonesia; \\ ${ }^{2}$ Faculty of Medicine, University of Brawijaya, Malang, Indonesia \\ ${ }^{3}$ Faculty of Medicine, University of Brawijaya, Malang, Indonesia \\ ${ }^{4}$ Neurology Department of Saiful Anwar General Hospital, University of Brawijaya, Malang, Indonesia
}

\section{Article History:}

Received: January 24, 2020

Accepted: December 1, 2020

Published: January 1, 2020

\section{Cite this as:}

Wardani R, Salsabila S,

Novrianto A, Rakhmatiar $R$.

Effectivity of nintendo wii as

rehabilitation therapy in post

stroke patients: a systematic

review. Malang Neurology

Journal; 2021.7:56-59.

http://dx.doi.org/10.21776/ub.mnj

.2021.007.01.11

\section{ABSTRACT}

Post stroke patients need medical rehabilitation to live an independent life. Nintendo Wii technology presents an alternative choice that is quite safe, feasible, and has a high potential in rehabilitating \& restoring motor function in post stroke patients. Although it has been widely used as adjunct therapy in stroke rehabilitation facilities throughout the world, only a few acknowledge its effectivity in poststroke patients. This study aims to conduct a systematic review in order to identify and assess the results used in evaluating Nintendo Wii technology as rehabilitation therapy for stroke patients. Thus, the study used for this research is systematic review. Materials included in this study are research/studies found in NCBI, PubMed, Cochrane and other relevant online databases. From this research, it is found that Virtual Reality (VR) such as Nintendo Wii considered as an additional rehabilitation therapy that provides a significant improvement in various aspects of exercise therapy, such as; balance; walking ability; statistical and dynamic strengths; motivation as well as socialization; and recovery of physical function in stroke patients. Nintendo Wii can also be used safely in stroke patients and there have been no reports of side effects from this therapy.

Keywords: Stroke, nintendo wii, rehabilitation, therapy

\section{Introduction}

Stroke is defined as a state of partial or total loss of neurological function (focal or global neurological deficits) that occurs suddenly, lasts more than 24 hours or causes death, which is solely caused by circulatory disorder of the brain due to reduced blood supply which is also called an ischemic stroke or spontaneous rupture of blood vessels known as hemorrhagic stroke. ${ }^{1}$ In 2012, WHO data revealed that stroke is the leading cause of disability and the second cause of death worldwide. The total number of stroke patients based on healthcare workers' diagnosis in 2013 was $1,236,825$ people $(7.0 \%)$ and based on symptoms were $2,137,941$ people $(12.1 \%) .^{2}$

Stroke management is generally divided into two stages. The first stage is the acute stage, where the goal of treatment is to save neurons and prevent other pathological processes that possibly threaten brain function. The second stage is the post acute stage or the recovery stage, where patients need more comprehensive treatment to minimize disability. ${ }^{3}$ For post-stroke patients, medical rehabilitation interventions are needed so that they are able to independently take care of themselves and carry out daily life activities without being a burden to their families and surroundings.
Ischemic stroke will cause hypoxia and cause damage to brain neurons. However, brain neurons have plasticity, which has the potential to adapt to changes and compensate for the loss of function in other parts of the brain to restore normal brain function. ${ }^{4}$

Over the course of time, more effective stroke therapies have developed to prevent the severity of brain damage area. Nowadays, neuroscience research proves that there are neuroplasticity and neuro-regeneration activity in the central nervous system that runs in a human's body. The ability of the brain to learn new behaviors, form new memories, and change involved neural structures that are responsible for learning is called neuroplasticity. ${ }^{5}$

On the other hand, neuro-restoration is one of the active procedures involved in repairing damaged nervous systems functionally and pathologically. This neuro-restoration includes the process of forming new neurons (neurogenesis), new vascularization (angiogenesis), and the formation of synapses between neurons (synaptogenesis). It is hoped that the development of neuro-restoration therapy can reduce stroke morbidity in the future. ${ }^{6}$

Various factors regulate neurogenesis in the brain which also play a role in the neurogenic response to ischemic injury, one of which is rehabilitation/post-stroke training. 
Table 1. Data Extraction

\begin{tabular}{lllll}
\hline References & Objectives & Methodology & Result \\
\hline $\begin{array}{l}\text { Bang et al } \\
2016^{11}\end{array}$ & $\begin{array}{l}\text { To investigate the } \\
\text { effects of }\end{array}$ & $\begin{array}{l}\text { 40 stroke patients divided into 2 groups: } \\
\text { virtual reality training group and treadmill }\end{array}$ & $\begin{array}{l}\text { Both groups revealed a notable } \\
\text { difference in left/right and anterior/ } \\
\text { Nintendo Wii } \\
\text { on balance and } \\
\text { walking for stroke } \\
\text { patients. }\end{array}$ & $\begin{array}{l}\text { group. Both groups completed a 40-minute } \\
\text { exercise 3x/week for 8 weeks. Their } \\
\text { balance and ability to walk were measured } \\
\text { before the program had started and after } \\
\text { significant difference in the stance } \\
\text { phase, swing phase, and cadence also } \\
\text { showed in the VR training group. }\end{array}$ \\
& & &
\end{tabular}

$\begin{array}{llrl}\text { Tülay } & \text { To analyze the } & \text { The sample population was } 42 \text { strok } \\ \text { Tarsuslu } & \text { outcomes } & \text { of } & \text { patients with a mean age of } 58.04 \text { and the }\end{array}$

Şimşek \& balance and upper average stroke recurrence time was 55.2

Kübra extremity training

Çekok program using

$(2015)^{9} \quad$ Nintendo Wii on

subacute stroke

patients' daily

living activities and quality of life.

days $\sim 8$ weeks.

Participants were randomly assigned to join the Nintendo Wii group $(n=20)$ and the Bobath Neuro Developmental Treatment (NDT) group.

Visual Analog Scale (VAS) used as an assessment tool for satisfaction evaluation during the training.

However, at the end of the training program (10 weeks), further evaluation was executed using the Functional Independence Measure (FIM) and the Nottingham Health Profile (NHP). FIM was the assessment tool used to evaluate the functional status of patients throughout the rehabilitation process, as well as their functional independence in carrying out daily life activities. On the other hand, NHP was the assessment tool used to evaluate patients' health-related quality of life.

$\begin{array}{ll}\text { Ayca et al } & \text { To analyze the } \\ 2018^{12} & \text { effectiveness of } \\ \text { balance } & \\ & \text { rehabilitation } \\ \text { program using the } & \text { Nintendo Wii as } \\ & \text { an adjunct therapy } \\ & \text { to conventional } \\ & \text { method. }\end{array}$

Evaluate 23 stroke patients using Berg Balance Scale, Functional Reach Test, Postural Assessment Scale. Further assessment was performed using postural sway and transfer and ambulation scores. Follow up procedure was done 4 weeks after the completion of the study.
There was a significant difference between FIM and NHP values in NDT and Nintendo Wii groups.

There was a significant difference between FIM and NHP values in NDT and Nintendo Wii groups. However, there was no significant difference found between groups regarding FIM and NHP evaluation.

It showed that the Nintendo Wii group has a higher satisfaction measure towards the therapy compared to the NDT group. In both groups, a notable difference were found between subparameters and total FIM score, all sub-parameters, and total NHP score.
Conclusion

This study implies that

virtual reality training which provides visual feedback allows stroke patients to correct their weight center and move visually. VR training most likely fit patients who wan to regain their balance and walking ability by encouraging their interest to carry out programmed exercises regularly.

This study proved that the Nintendo Wii training program was as effective as Bobath NDT in improving subacute stroke patients' functional independence in carrying out daily life activities and quality of life.

\begin{tabular}{|c|c|}
\hline $\begin{array}{l}\text { Hilland et } \\
\text { al, } 2018^{13}\end{array}$ & $\begin{array}{l}\text { To conduct an in- } \\
\text { depth analysis of } \\
\text { the benefits and } \\
\text { challenges } \\
\text { regarding the use } \\
\text { of the Nintendo } \\
\text { Wii as stroke } \\
\text { rehabilitation } \\
\text { training at home } \\
\text { from the } \\
\text { perspective of } \\
\text { patients and } \\
\text { practitioners. }\end{array}$ \\
\hline
\end{tabular}

15 physiotherapists and 19 stroke patients were interviewed after including Nintendo Wii as therapy at home for 6 weeks

\section{There are significant differences using Berg Balance Test and Functional Reach Test}

Post stroke rehabilitation therapy using Nintendo Wii increase static and dynamic balance on post stroke patients.

\section{From the interview results, it is found Nintendo Wii is a fun form that there are 4 advantages of using Nintendo Wii during home-based stroke rehabilitation, which are physical, psychological, social and cognitive. In terms of physical health, it improved balance and strength. It is also physiologically motivating, fun, and help increase involvement with physiotherapists/others. Socially, it able to increase socialization with family and friends. In terms of

\author{
of rehabilitation, \\ promoting the involvement \\ of physiotherapists / others, \\ increasing motivation as \\ well as social opportunities \\ in home-based therapy. \\ Nintendo Wii might be a \\ promising strategy that can \\ be used as an adjunct to \\ stroke rehabilitation at \\ home.
} cognitive improvement, it able to increase concentration/attention.
A total of 30 stroke patients with a mean age of 65 years old were observed for 8 weeks. They were divided into 2 groups; the Nintendo Wii group $(50 \%)$ and the control group $(50 \%)$. The assessment of the intervention carried out by evaluating attention and processing speed (TMT-A dan B) and working memory (Digit Span of WAIS-III). The results of improvement on both groups were compared and analyzed using effect size tests and parametric tests.

\begin{tabular}{|c|c|}
\hline $\begin{array}{l}\text { The group that intervened with } \\
\text { Nintendo Wii had better results in } \\
\text { attention and speed compared to the } \\
\text { control group. Working memory was } \\
\text { measured using the WAIS-III Digit } \\
\text { Span task. Based on the Digit Span } \\
\text { Forward (DST Forward SS) task, the } \\
\text { Nintendo Wii group had a better result } \\
\text { than the accumulation of the control } \\
\text { group regarding the effect size. }\end{array}$ & $\begin{array}{l}\text { This study showed a } \\
\text { positive result on the } \\
\text { recovery of physical } \\
\text { function in targeted stroke } \\
\text { patients using Nintendo } \\
\text { Wii. Although the evidence } \\
\text { is not conclusive, results } \\
\text { indicate beneficial } \\
\text { outcomes in stroke patients } \\
\text { who use Nintendo Wii, } \\
\text { particularly in their area of } \\
\text { attention and speed } \\
\text { processing. }\end{array}$ \\
\hline
\end{tabular}


Post-ischemic stroke exercises are most effective if performed immediately after the acute phase. Daily rehabilitation which target fine motor and lower limb function can improve functional outcomes after ischemic stroke. ${ }^{7}$

Previous research has revealed that exercise or physical activity can provide neurological benefits and preservative effects on the brain, prevent cognitive decline, and improve cognitive performance. Research using animal models revealed that exercise potentially increases neurotrophic factors, glial cell activity, and cerebral blood flow. Thus, increasing the neurogenesis and neuron cell viability. ${ }^{8}$

Stroke rehabilitation is known as a learning method where motor learning mechanisms are operative and related to spontaneous recovery. ${ }^{9}$

Virtual Reality (VR) and interactive video games appeared as a new treatment strategy in a stroke rehabilitation center. Nintendo Wii is considered a simple and practical virtual therapy option that used in stroke rehabilitation units throughout the world. ${ }^{10}$

Through some research, it is found that the Nintendo Wii improves stroke patients' ability in carrying out daily life activities independently by increasing the upper limb function.

Nintendo Wii is confirmed to be safe and effective to recover upper limb function as balance training, which potentially becomes a great rehabilitation alternative for stroke patients. ${ }^{9}$

\section{Method}

The Each author did a thorough survey during May-June 2019 through several online databases such as NCBI, PubMed, and Cochrane using PICO as a search strategy. Keywords used were: stroke, Nintendo Wii, and medical rehabilitation. The systematic review created by following PRISMA (Preferred Reporting Items for Systematic reviews and meta-analysis) guidelines.

\section{Inclusion Criteria}

Journals related to the use of Nintendo Wii as rehabilitation therapy of post-stroke patients for the past five years.

\section{Exclusion Criteria}

Editorial, articles, and meta-analysis were excluded due to the unavailability of desired data in order to create a systematic review.

\section{Data Extraction}

Data extraction related to several journals/studies was carried out using standard tables developed by authors. The table consisted of; (1) Main author and year of publication; (2) Research objectives; (3) Methodology; (4) Research results; and (5) Conclusions.

\begin{tabular}{|c|c|c|c|}
\hline $\begin{array}{c}\mathbf{P} \\
\text { (Patient) }\end{array}$ & $\begin{array}{c}\text { I } \\
\text { (Intervention) }\end{array}$ & $\begin{array}{c}\mathrm{C} \\
\text { (Comparison) }\end{array}$ & $\begin{array}{c}\mathbf{O} \\
\text { (Outcome) }\end{array}$ \\
\hline $\begin{array}{l}\text { Male and } \\
\text { female stroke } \\
\text { patients aged } \\
18-70 \text { years } \\
\text { old who still } \\
\text { experience } \\
\text { stroke sequel. }\end{array}$ & $\begin{array}{l}\text { An intervention } \\
\text { was carried out } \\
\text { on the } \\
\text { rehabilitation of } \\
\text { stroke patients } \\
\text { using the } \\
\text { Nintendo Wii. }\end{array}$ & $\begin{array}{l}\text { Compared to } \\
\text { conventional } \\
\text { training or other } \\
\text { exercises. }\end{array}$ & $\begin{array}{l}\text { Bring up new } \\
\text { innovations in } \\
\text { stroke } \\
\text { patients' } \\
\text { rehabilitation } \\
\text { by using } \\
\text { Nintendo Wii } \\
\text { to improve } \\
\text { rehabilitation } \\
\text { results and } \\
\text { patient } \\
\text { compliance. }\end{array}$ \\
\hline
\end{tabular}

\section{Results}

Data extraction was performed to selected studies put into tables that have been developed by the authors.

\section{Discussion}

After reviewing five selected journals, it is found that there are evidences related to the effectivity of Nintendo Wii as rehabilitation therapy in stroke patients. Several studies have shown that Nintendo Wii provides a significant improvement in balance and walking ability in stroke patients who have intervened for 8 weeks. One of the reviewed-study also shows improvement in static and dynamic strength in stroke patients who undergone rehabilitation therapy with Nintendo Wii for 4 weeks. Nintendo Wii is highly recommended as additional therapy at home due to the fact that it can increase motivation as well as socialization of stroke patients. In addition, Nintendo Wii also showed positive results in physical function recovery of stroke patients after 8 weeks of exercise. However, another studies also show that Nintendo Wii has the same effectivity as Bobath NDT therapy in improving daily life activity functioning as well as quality of life in stroke patients. Due to limited available data related to this topic, further research focusing on Nintendo Wii as rehabilitation therapy for post stroke patients need to be done.

Table 2. Data Assessment

\begin{tabular}{|c|c|c|c|c|}
\hline Author & Year & Sample Population & Exercise Duration & Result \\
\hline Bang et al & 2016 & 40 & $\begin{array}{l}8 \text { weeks } \\
\text { (40 minutes/day, } 3 \text { days/week) }\end{array}$ & $\begin{array}{l}\text { There is a significant improvement in balance and } \\
\text { walking ability in patients who have intervened with } \\
\text { Nintendo Wii. }\end{array}$ \\
\hline Ayca et al & 2018 & 23 & $\begin{array}{l}4 \text { weeks } \\
\text { ( } 20 \text { minutes/day, } 5 \text { days/week) }\end{array}$ & $\begin{array}{l}\text { Stroke patients who undergone rehabilitation therapy } \\
\text { with Nintendo Wii shows improvement in static and } \\
\text { dynamic strength. }\end{array}$ \\
\hline Hilland et al & 2018 & 19 & 6 weeks (30 minutes/day) & $\begin{array}{l}\text { Nintendo Wii improve motivation as well as } \\
\text { socialization and considered as a promising strategy } \\
\text { for adjunct therapy for stroke rehabilitation at home. }\end{array}$ \\
\hline Markaida et al & 2019 & 30 & $\begin{array}{l}8 \text { weeks ( } 30 \text { minutes/day, } 3 \\
\text { days/week) }\end{array}$ & $\begin{array}{l}\text { Nintendo Wii shows positive result in recovering } \\
\text { physical function in stroke patients. }\end{array}$ \\
\hline
\end{tabular}




\section{Conclussion}

From this study, it is found that rehabilitation in stroke patients using Virtual Reality such as the Nintendo Wii can be included as additional therapy that provides a significant improvement in various aspects of exercise therapy, such as; balance; walking ability; statistical and dynamic strengths; motivation as well as socialization; and recovery of physical function in stroke patients. Nintendo Wii can also be used safely in stroke patients and there have been no reports of side effects from this therapy. More research that includes Nintendo Wii as rehabilitation therapy for post stroke patients need to be done due to limited available data worldwide.

\section{Acknowledgment}

Authors thank everyone who was involved in previous studies for providing relevant data which were used to compose this research.

\section{Refferences}

1. Perdossi. Stroke Guideline. Jakarta: Indonesian Neurologist Association; 2011.

2. Ministry of Health of the Republic of Indonesia. Basic Health Research 2013. Jakarta: Indonesian Agency for Health Research and Development; 2013.

3. National Institute of Neurological Disorder and Stroke; 2008. Avalaible form: http://www.ninds.nih.gov/

4. Lie, et al. Brain Neuron Regeneration in Post-Stroke Rehabilitation. Malang Neurology Journal; 2016. 2(1):19-23.

DOI: http://dx.doi.org/10.21776/ub.mnj.2016.002.01.4

5. Glass BD, Maddox WT, Love BC. Real-time strategy game training: Emergence of a cognitive flexibility trait. PLOS One: United Kingdom; 2013.

DOI: https://doi.org/10.1371/journal.pone.0070350

6. Widjaja, Putra. Neurorestorasi pasca-stroke: Harapan baru penderita stroke. CME CDK; 2015. 227;257-261. Avalaible form: http://www.cdkjournal.com/
7. Lichtenwalner RJ, Parent JM. Adult neurogenesis and the ischemic forebrain. J Cereb Blood Flow Metab; 2006. 26: 1-20. DOI: 10.1038/sj.jcbfm. 9600170

8. Rivarti AW, Herawati L, Hidayati HB. Exercise prevents age- related memory decline: the role of neurotrophic factors. Malang Neurology Journal; 2020.6:88- 94. DOI: 10.21776/ub.mnj .2020.006.02.8

9. Simsek TT \& Cekok K. The effects of Nintendo WiiTM-based balance and upper extremity training on activities of daily living and quality of life in patients with sub-acute stroke: A randomized controlled study. International Journal of Neuroscience; 2015. Available from: http://www.tandfonline.com/action/journalInformation ?journalCode=ines 20

10. Aguiar et al. The use of nintendo wii in the rehabilitation of poststroke patients: A systematic review. journal of stroke and cerebrovascular diseases. National Stroke Association; 2015.

DOI: 10.1016/j.jstrokecerebrovasdis.2015.06.010

11. Bang et al. Effects of virtual reality training using nintendo wii and treadmill walking exercise on balance and walking for stroke patients. Journal of Physical Therapy Science; 2016. Avalaible from: https://www.ncbi.nlm.nih.gov/pmc/articles/PMC5140 $810 /$

12. Ayca et al. Effectiveness of wii-based rehabilitation in stroke: A randomize controlled study. Journal of Rehabilitation Medicine; 2018. Avalaible form: https://www.medicaljournals.se/jrm/content/html/10.2 340/16501977-2331

13. Hilland et al. An evaluation of the nintendo wiitm as a home-based stroke rehabilitation intervention: a qualitative interview study. SM Phys Med Rehabil; 2018. 2(1): 1002.

Avalaible form: https://smjournals.com/physicalmedicine/fulltext/smpmr-v2-1002.php

14. Markaida et al. Effect of the wii sports resort on the improvement in attention, processing speed and working memory in moderate stroke. Journal of Neuroengineering and Rehabilitation; 2019. 16:32. DOI: $10.1186 / \mathrm{s} 12984-019-0500-5$ 